\title{
Inverse scope and unaccusativity alternation
}

Satoshi Oku*

\begin{abstract}
In this paper, I first review evidence for the claim that there is an inverse correlation between Japanese scrambling and QR: that is, Japanese is scope rigid because it allows scrambling as a syntactic option (Szabolcsi 1997, Bobaljik and Wurmbrand 2012). According to Bobaljik and Wurmbrand's approach, QR is blocked in Japanese because Japanese has scrambling. There are, however, cases in which apparent inverse scope is easily available in Japanese (Oku 2010), which is problematic to Bobaljik and Wurmbrand and to any theoretical attempt to account for Szabolcsi's inverse correlation. To explain this conflicting situation, I will propose that verbs involved in such apparent counterexamples are actually unaccusatives so that the surface subject is the underlying complement of the verb: the apparent inverse scope is read off at the underlying structure where the surface subject is c-commanded by the PP. As independent evidence for the unaccusasivity of the verbs in question, I will show that the floating quantifier fact (Miyagawa 1989) confirms what I propose. Further, the unaccusativity alternation in Japanese (reported by Yamada 1998) is endorsed by the inverse scope facts explored in this paper.
\end{abstract}

Keywords. inverse scope; Japanese scrambling; QR; unaccusativity; floating quantifier

1. Introduction. It has been observed that when a sentence has two (or more quantificational expressions), the sentence may show scope interaction (May 1985, etc.). For instance, an English sentence (1) is claimed to have the inverse scope interpretation as in (2b), as well as the surface order scope interpretation shown in (2a).

(1) A girl recommended every boy.

(2) a. There is $x, x$ a girl such that for every $y, y$ a boy, $x$ recommended y. $\quad(\exists>\forall)$

b. For every y, $\mathrm{y}$ a boy, there is $\mathrm{x}, \mathrm{x}$ a girl such that $\mathrm{x}$ recommended $\mathrm{y} . \quad(\forall>\exists)$

It is also well known that English does not have "scrambling" in the same sense as scrambling in Japanese as shown in (3).

(3) a. * Every boy $i$, a girl recommended $t_{i}$.

b. John handed the book to Mary.

c. * To Mary $y_{j}$, the book $k_{i}$, John handed $t_{i} t_{j}$.

d. Mary didn't go anywhere.

e. * Anywhere ${ }_{i}$, Mary didn't go $t_{i}$.

\footnotetext{
* I thank the audience who were interested in my poster presentation and gave comments and questions at the LSA Annual Meeting (January 2018, Salt Lake City). Earlier versions of parts of this paper have been presented at NINJAL workshops (December 2016, December 2017, Tachikawa), and the 62nd General Meeting of the English Literary Society of Japan, Hokkaido Branch (October 2017, Sapporo). I am grateful to the audiences in these occasions for comments and feedbacks, especially to Mamoru Saito and Željko Bošković. I also thank Koji Hoshi and Masahiko Takahashi for invaluable discussion. Any errors and inadequacies are, of course, my own. Author: Hokkaido University (satoshio@imc.hokudai.ac.jp).
} 
Japanese, on the other hand, is claimed to be a scope rigid language, and thus in the comparable Japanese sentence in (4), the inverse scope interpretation in (5b) is hard to obtain (e.g., Kuroda 1965, Kuno 1973, Hoji 1985. Lasnik and Saito 1992, Bobaljik and Wurmbrand 2012).

$\begin{array}{lllll}\text { Onnanoko-ga } & \text { hitori } & \text { dono } & \text { otokonoko-mo } & \text { suisensita. } \\ \text { girl-NOM } & \text { one } & \text { every } & \text { otokonoko- MO } & \text { recommended }\end{array}$

'A girl recommended every boy'

(5) a. There is $x, x$ a girl such that for every $y, y$ a boy, $x$ recommended $y .(\exists>\forall)$

b. *For every $\mathrm{y}, \mathrm{y}$ a boy, there is $\mathrm{x}, \mathrm{x}$ a girl such that $\mathrm{x}$ recommended $\mathrm{y} .(* \forall>\exists)$

Meanwhile, Japanese is a scrambling language and thus allows much freer word order variation (Kuroda 1965, Saito 1985, among many others).
a. Dono otokonoko-mo ${ }_{i}$ onnanoko-ga every otokonoko- MO girl- NOM lit. 'every boy, a girl recommended'
b. Taroo-wa Mary-ni sono hon-o Taroo-TOP Mary-to the book-ACC 'Taro handed the book to Mary'
c. Mary-ni ${ }_{i}$ sono hon-oj Mary-to the book-ACC Taroo- TOP handed
d. Mary-wa doko-ni-mo ikanakatta. Mary- TOP where-to- MO go-NEG-PAST
'Mary didn't go anywhere'
e. Doko-ni-mo ${ }_{i}$, Mary-wa t $_{i}$ ikanakatta.
where-to- Mo Mary- TOP go-NEG-PAST
hitori $\mathrm{t}_{i} \quad$ suisensita. $\quad(\forall>\exists)$ one recommended watasita. handed

$\begin{array}{ll}\text { Taroo-wa } \mathrm{t}_{i} \mathrm{t}_{j} & \text { watasita. } \\ \text { Taroo- TOP } & \text { handed }\end{array}$

Given this and similar observation in a number of languages, Szabolcsi (1997) observes that there is a general "inverse correlation" tendency as in (7).

"inverse correlation"

a. languages with free word order: rigid scope

b. languages with strict possibilities of word order: tolerance for scope ambiguity

That is, Japanese is a free word order language as shown in (6) and at the same time it does not allow the inverse scope interpretation as in (4) and (5). English, in contrast, exhibits strict possibilities of word order as shown in (3) and at the same time it easily allows the inverse scope interpretation as shown in (1) and (2).

An obvious question to be raised is what is the source of this "inverse" correlation. To answer this question, Bobaljik and Wurmbrand (2012) proposes (8).

(8) Scope Transparency (ScoT)

If the order of two elements at LF is $\mathrm{A}>>\mathrm{B}$, the order at PF is $\mathrm{A}>>\mathrm{B}$.

(Bobaljik and Wurmbrand 2012: 373)

For example, if you want the $\forall>\exists$ scope interpretation in a given sentence, use the word order which transparently corresponds to that scope interpretation. In Japanese, the surface order in (6a) is grammatically allowed (scrambling is syntactically available), and thus (6a) is given a priority to (4) when you want the $\forall>\exists$ scope interpretation. English, however, does not allow 
scrambling as in (3a), and thus when you want the $\forall>\exists$ scope interpretation, you may be allowed to use the less transparent sentence in (1): LF order and PF order can be mismatched, or QR is possible. Crucially, Bobaljik and Wurmbrand (2012) state the following:

(9) “... inverse scope in [4] is blocked by the availability of [6a], which is a more transparent reflection of the scope. QR is possible in this context in English, precisely because English lacks scrambling." See (3a). (Bobaljik \& Wurmbrand 2012:373. The underline is the author's)

In this paper, I am going to show that there are cases in Japanese which apparently go against (8) and then argue that such cases involve unaccusative verbs. I will further show that unaccusativity alternation cases in Japanese behave in the expected fashion in terms of scope.

2. Unaccusativity. There are clear cases in Japanese which go against Bobaljik and Wurmbrand's (2012) generalization in (8) - (9). Look at the sentences in (10), where the inverse scope interpretation is not just allowed but is strongly preferred.
a. TA-ga futari
dono CALL kyoositu-ni-mo taikisita.
TA-NOM two
every CALL room-in- MO
were-on-standby
'Two TAs were on standby in every CALL room'
b. Gaadoman-ga futari dono iriguti-ni-mo tatteiru.
guard- NOM two every gate-at- MO standing
'Two guards are standing at every gate'
c. SP-ga hitori dono VIP-ni-mo harituita. SP- NOM one every VIP-to- MO stuck-to
'An SP guarded every VIP'
$(\forall>2 ; \# 2>\forall)^{1}$

$$
\begin{aligned}
& (\text { Oku 2010) } \\
& (\forall>2 ; \# 2>\forall) \\
& (\forall>\exists ; \# \exists>\forall)
\end{aligned}
$$

Crucially, the existence of the more transparent scrambled versions in (11) below does not block the inverse scope reading of the sentences in (10), contrary to what Bobaljik and Wurmbrand expect. Recall (9), repeated here as (12) (with the relevant renumbering).
a. Dono CALL kyoositu-ni-mo TA-ga every CALL room-in-MO TA-NOM
futari taikisita.
$(\forall>2 ; \# 2>\forall)$ 'In every CALL room, two TAs were on standby'
b. Dono iriguti-ni-mo gaadoman-ga futari tatteiru. every gate-at-MO guard- NOM two standing 'At every gate, two guards are standing'
c. Dono VIP-ni-mo SP-ga hitori every VIP-to-MO SP- NOM one stuck-to harituita. lit. 'Every VIP, an SP guarded' “... inverse scope in [10] is blocked by the availability of [11], ...”

(Bobaljik and Wurmbrand 2012:373)

To solve this problem, I would like to propose that the class of verbs which allows the inverse scope reading is unaccusative (see Levin and Rappaport 1998).

\footnotetext{
${ }^{1}$ I believe that the surface order scope ( $2>\forall$ ) is syntactically and semantically available as well in (56), but it is just pragmatically odd, for which I assign a double cross \# mark. See Reinhart (2006) for the relevant discussion.
} 


\section{Proposal}

Verbs in (10) are unaccusative verbs: the surface subject is the underlying complement of the verb.

Therefore, the underlying structure of (10a), for instance, is (14).

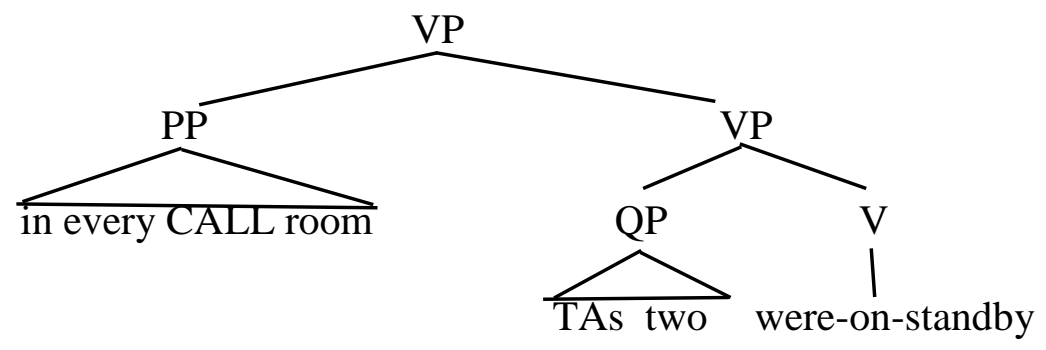

The $\forall>2$ scope for (10a) is determined at this stage of derivation in (14), where the universally quantified PP c-commands the numeral QP. To the extent that the primary scope relation is read off at the stage of derivation in which the relevant two phrases are introduced, the strong preference of the $\forall>2$ reading in (10a) is neatly accounted for. [Qp TA-ga futari] 'TAs-NOM two' in (14) may move to the surface subject position to get the surface order in (10a). The same analysis applies to the other two verbs in (10).

3. Unaccusativity: Floating Quantifier Test. Are there any independent evidence that verbs in (10) are unaccusatives? It is known that in Japanese transitive sentences, the subject floating quantifier (FQ) is not possible while the object FQ is possible (Miyagawa 1989).

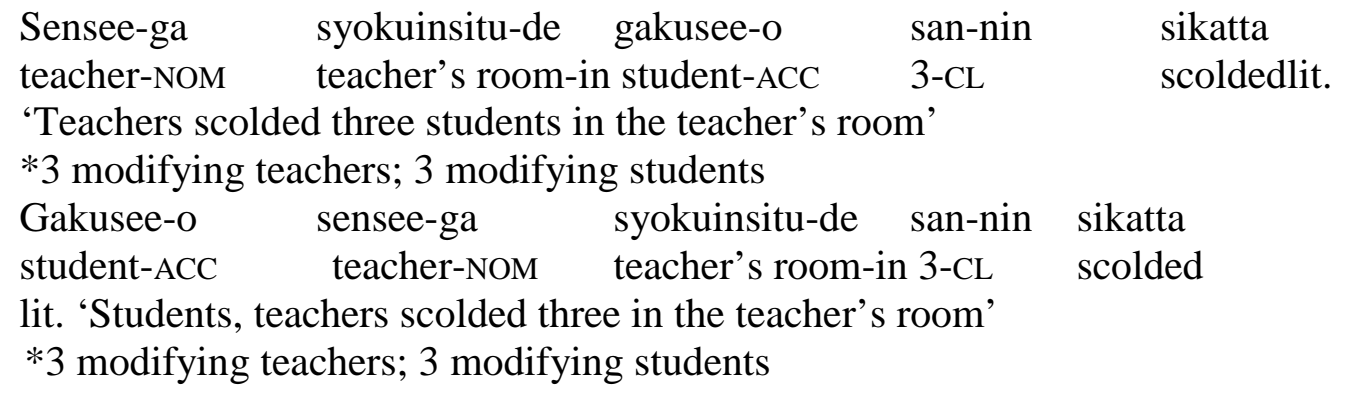

According to Miyagawa (1989), the object NP gakusee-o 'student-ACC' and the numeral quantifier 3-CL mutually c-command each other in (15), which makes the object FQ in (16) possible. On the other hand, there is no point of derivation in which the subject and the numeral quantifier in (15) mutually c-command, and thus the subject FQ is not possible in (15).

Now, Miyagawa claims that the FQ test can tell unaccusative verbs from unerative verbs. The former allows the subject FQ since the surface subject is in the complement position underlyingly where the NP and the quantifier mutually c-command. The latter (i.e., unergative verbs), in contrast, does not allow FQ. A typical unaccusative verb iru 'exist', for example, allows the subject FQ as in (17). The relevant derivation is as illustrated in (18).

$\begin{array}{llll}\text { (17) TA-ga sono CALL kyoositu-ni } & \text { futari } & \text { iru. } \\ \text { TA-NOM that CALL room-in two } & \text { exist } \\ & \text { lit. 'TAs are two in }\end{array}$


(18)

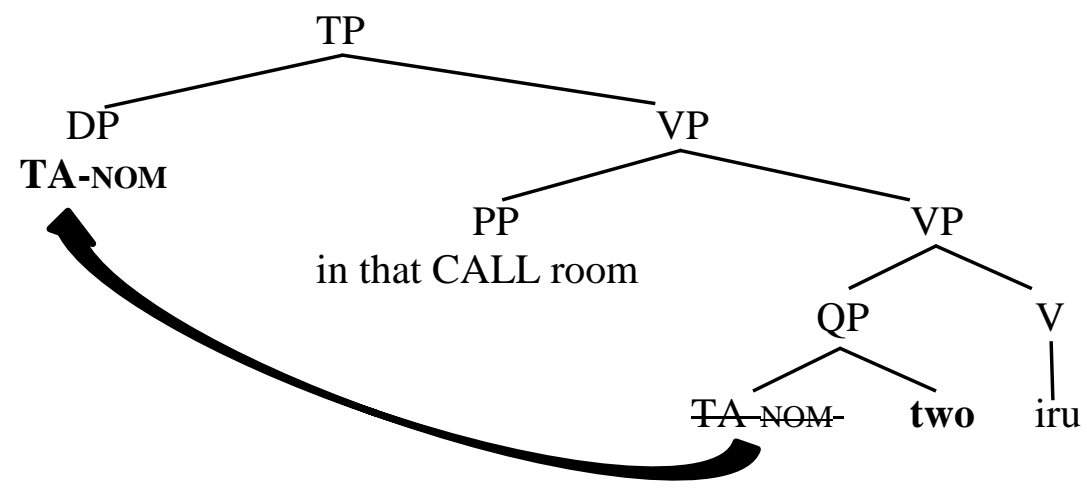

And as expected, the inverse scope reading is also available with the genuine unaccusative verb iru 'exist' as in (19).

(19) TA-ga futari dono CALL kyoositu-ni-mo iru. $(\forall>2$; \# $2>\forall)$

TA-NOM two every CALL room-in-MO exist

'Two TAs are in every CALL room'

Now we have claimed that verbs in (10) are all unaccusatives, based on the fact that the inverse scope reading is strongly preferred. Now since FQ is possible with unaccusatives, it is precited that the verbs in (10) also allows FQ.

(20) Prediction

If the inverse scope is easily available (strongly preferred), then it is predicted that the verb is unaccusative and thus floating quantifier is possible.

I am going to show that the prediction is borne out. Look at (21) through (23).
a. TA-ga futari dono CALL kyositu-ni-mo taikisita.
$(=(10 \mathrm{a})) \quad(\forall>2)$
TA-NOM two every CALL room-in-MO were-on-standby
'Two TAs were on standby in every CALL room'

b. TA-ga dono CALL kyositu-ni-mo futari

TA-NOM every CALL room-in-MO

two

taikisita. lit. 'TAs were on standby two in every CALL room'

a. Gaadoman-ga futari dono iriguti-ni-mo tatteiru. guard- NOM two every gate-at- MO standing 'Two guards are standing at every gate'
b. Gaadoman-ga dono iriguti-ni-mo futari tatteiru. guard- NOM every gate-at- MO two standing

lit. 'Guards are two standing at every gate'

(23) a. SP-ga hitori dono VIP-ni-mo harituita. $(=(10 \mathrm{c}))(\forall>\exists ; \# \exists>\forall)$ SP- NOM one every VIP-to- MO stuck-to 'An SP guarded every VIP'
b. SP-ga dono VIP-ni-mo hitori SP-NOM every VIP-to-MO one harituita. lit. 'An SP guarded one every VIP' stuck to 
The (b) sentences in (21)-(23) are perfect, which exhibits a sharp contrast with transitive sentences and unergative sentences as shown in (24) and (25).

(24) transitive verb

a. TA-ga futari dono CALL kyositu-ni-mo sezyosita. $(2>\forall ; * \forall>2)$ TA-NOM two every CALL room-in-MO locked

'Two TAs locked every CALL room'

$\begin{array}{cccc}\text { b. *TA-ga } & \text { dono CALL kyositu-ni-mo } & \text { futari } & \text { sezyosita. } \\ \text { TA-NOM } & \text { every CALL room-in-Mo } & \text { two } & \text { locked }\end{array}$

lit. 'TAs locked two every CALL room'

(25) unergative verbs ${ }^{2}$

a. TA-ga futari dono CALL kyositu-de-mo geragerato waratta $(2>\forall$; ?? $\forall>2)$ TA-NOM two every CALL room-in-MO loudly laughed

'Two TAs loudly laughed in every CALL room'

b.?? TA-ga dono CALL kyositu-de-mo geragerato futari waratta

TA-NOM every CALL room-in-MO loudly two laughed lit. 'TAs loudly laughed two in every CALL room'

4. Unaccusativity Alternation. In this section, I will argue that the inverse scope fact give a new piece of evidence for the claims that a Japanese verbal affix -teiku 'and-go' induces unaccusativity alternation (Yamada 1998).

Since Levin and Rappaport (1998), it has been known that an unergative verb acquires unaccusativity under certain morpho-syntactic conditions. In English, for instance, unaccusative verbs allow a secondary predicate without a fake reflexive as in (26). In contrast, unergative verbs require a fake reflexive in order to have a secondary predicate as shown in (27).

(26) unaccusative

a. The river froze solid.

b. *The river froze itself solid.

(27) unergative

a. * John ran exhausted.

b. John ran himself exhausted.

Interestingly, however, if we add a direction complement like clear of the car, an unergative verb alternaties into an unaccusative verb.

(28) a. John ran clear of the car.

b. * John ran himself clear of the car.

Expanding the general idea of unaccusativity alternation explored in Levin and Rappaport (1998), Yamada (1998) argues that when a Japanese verbal affix -teiku 'and-go' is attached to a motion type unergative verb, the verb acquires unaccusativity. As we have seen in (25b) above, Japanese unergative verbs do not allow FQ, which sharply contrasts with unaccusative verbs which allow FQ. Yamada shows that the same is true for motion type unergative verbs in Japanese. That is, FQ is not allowed as in (29).

\footnotetext{
${ }^{2}$ See Miyagawa (1989: 41-45) for more discussion and data on unergative verbs.
} 
$\begin{array}{lll}\text { (29) * Kodomotati-ga [vp te-o tunaide hiroba-de } & \text { san-nin } & \text { hasitta]. } \\ \text { children-NOM hand-ACC holding square-in } & \text { 3-CL } & \text { ran }\end{array}$

lit. 'Children ran three holding hands in the square'

Yamada then shows that in (30) where the unergative hasir 'run' has an affix -teiku 'and-go,' FQ becomes possible. This indicates that hasitteiku 'run and-go' is an unaccusative verb, Yamada claims.

(30) Kodomotati-ga [vp te-o tunaide koen-e san-nin hasitteitta]. children-NOM hand-ACC holding park-to 3-CL ran-and-went lit. 'Children ran-and-went three holding hands to the park'

Although Yamada uses the FQ test for the unaccusativity in the sentences in question, we predict that inverse scope interpretation becomes easily available if we add the affix -teiku 'and-go' to unergative verbs. The fact is exactly what we expect as shown in (31).
a. Kodomotaci-ga futari [vp dono hiroba-de-mo
hasitta].
$(2>\forall ; ? ? \forall>2)$
children-NOM two every square-in-MO
ran
'Two children ran in every square'
b. Kodomotaci-ga futari [vp dono koen-e-mo children-NOM two every square-to-MO
hasitteitta]. $\quad(2>\forall ; \forall>2)$
'Two children ran-and-went to every park'
ran-and-went

The inverse scope reading is not easily to get in (31a), but in (31b) it is easily available.

5. Summary. In this paper, I first summarized the inverse correlation (Szabolcsi 1997) between Japanese scrambling and QR: that is, Japanese is scope rigid because Japanese allows scrambling as a syntactic option. Next, I introduced cases in which apparent inverse scope is easily available, which seems to be problematic to any theoretical attempt to account for Szabolcsi's inverse correlation. Then, I proposed that verbs involved in such apparent counterexamples are actually unaccusatives so that the surface subject is the underlying complement of the verb: the apparent inverse scope is read off at the underlying structure where the surface subject is c-commanded by the PP. The unaccusasivity is confirmed by the floating quantifier fact (Miyagawa 1989). Further, the unaccusativity alternation in Japanese (reported by Yamada 1998) is endorsed by the inverse scope fact explored in this paper.

\section{References}

Bobaljik, Jonathan D. and Suzi Wurmbrand. 2012. Word order and scope: transparent interfaces and the 3/4 signature. Linguistic Inquiry 43. 371-421.

Hoji, Hajime. 1985. Logical form constraints and configurational structures in Japanese. University of Washington dissertation.

Kuno, Susumu. 1973. The structure of the Japanese language. Cambridge, Massachusetts: MIT Press.

Kuroda, Shige-Yuki. 1965. Generative grammatical studies in the Japanese language. MIT dissertation.

Lasnik, Howard and Mamoru Saito. 1992. Move $\alpha$ : conditions on its application and output. Cambridge, Massachusetts: MIT Press.

Levin, Beth and M. Rappaport Havav. 1998. Unaccusativity: At the syntax-lexical semantics interface. Cambridge, Massachusetts: MIT Press. 
May, Robert. 1985. Logical form. Cambridge, Massachusetts: MIT Press.

Miyagawa, Shigeru. 1989. Syntax and semantics 22: Structure and case marking in Japanese. San Diego, California: Academic Press.

Oku, Satoshi. 2010. Toogo, zyoohookoozoo, ippan nintinoryoku (Syntax, information structure, and general cognition). In Nobuko Hasegawa (ed.), Toogoron-no sintenkai-to nihongo kenkyuu: meedai-o koete (New development of syntax and study of the Japanese language: Beyond proposition). 227-267. Tokyo: Kaitakusha.

Reinhart, Tanya. 2006. Interface strategies: optimal and costly computations. Cambridge, Massachusetts: MIT Press.

Saito, Mamoru. 1985. Some asymmetries in Japanese and their theoretical implications. MIT dissertation.

Szabolcsi, Anna. 1997. Strategies for scope taking. In Anna Szabolcsi (ed.), Ways of scope taking. 109-154. Dordrecht: Kluwer Academic Publishers.

Yamada, Yoshihiro. 1998. Doosa-no yootaidoosi-ni mirareru hitaikakusei-no kootai-ni tuite (On unaccusativity alternation observed in motion manner verbs). The Northern Review 26. 1344. 